\title{
ОЦЕНКА ИНВЕСТИЦИОННОЙ ПРИВЛЕКАТЕЛЬНОСТИ ПРЕДПРИЯТИЯ В СОВРЕМЕННЫХ УСЛОВИЯХ ХОЗЯЙСТВОВАНИЯ
}

\author{
(c) 2019 Козина Елена Вячеславовна \\ кандидат экономических наук, доцент кафедры экономики и управления \\ Пензенский государственный технологический университет, Россия, Пенза \\ E-mail: uhelena@list.ru \\ (C) 2019 Сурикова Д.С. \\ студентка 4 курса \\ Пензенский государственный технологический университет, Россия, Пенза \\ E-mail: surikova4997@mail.ru
}

В современных условиях хозяйствования, предприятия находятся в условиях жесткой конкурентной борьбы. Непрерывное развитие, быстрое приспособление к изменяющимся условиям как во внешней, так и во внутренней среде, производство актуального, качественного удовлетворяющий потребителя товара необходимо для стабильного развития организации. Что, в свою очередь, требует вложения инвестиций в основные средства, научно-технические и опытно-конструкторские разработки и на другие цели, направленные на увеличение производства, на повышение репутации компании. Для привлечения инвестиций организации следует грамотно управлять инвестиционной привлекательностью.

В статье представлены основные подходы к оценке инвестиционной привлекательности предприятия, исследована сущность понятия «инвестиционная привлекательность предприятия».

Ключевые слова: инвестиции, инвестиционная привлекательность, предприятие, анализ, коэффициенты, финансовая устойчивость, ликвидность, рентабельность.

Сегодня труды многих исследователей в области экономики посвящены проблеме определения понятия «инвестиционная привлекательность предприятия». В настоящее время не существует единого мнения относительно данной дефиниции.

Проанализировав различные подходы к трактовке данного понятия можно сказать, что «...инвестиционная привлекательность предприятия (далее ИПП) - это система экономических отношений между хозяйствующими субъектами по поводу эффективного развития бизнеса и поддержания его конкурентоспособности» [3, с. 92].

При вопросе вложения собственных средств в объект инвестирования инвестор оценивает факторы, влияющие на эффективность будущих инвестиций. Сочетания различных значений факторов многогранны, и поэтому инвестору необходимо дать оценку влияния и результатам их взаимодействия, т.е. оценить инвестиционную привлекательность социально-экономической системы и впоследствии принять решение о инвестировании. [1, с. 37].

Таким образом, появляется потребность в количественной оценке состояния инвестиционной привлекательности предприятия, учитывая то, что показатель, отражающий его состояние, должен содержать экономический смысл и быть сопоставимым с ценой капитала инвестора [2, c. 114].

Поэтому специалистами в области экономики, финансов и менеджмента сформулированы конкретные требования, предъявляемые к методике определения показателя инвестиционной привлекательности, которые учитывают самые весомые для инвестора факторы внешней и внутренней среды.

В настоящее время в отечественной и зарубежной экономической литературе описывается множество подходов к оценке инвестиционной привлекательности предприятия, среди которых можно выделить основные группы на основе факторов, положенных в методику ее оценки:

1) основываясь исключительно на финансовых показателях (М.Н. Крейнина, В.М. Аньшин, А.Г. Гиляровская, Л.Н. Чайникова, Л.В. Минько, Л.С. Тишина);

2) основываясь на данных финансово-экономического анализа предприятия, где оцени- 
ваются не только финансовые, но и производственные показатели (В.М. Власова, Э.И. Крылов, М.Г. Егорова, В.А. Москвин);

3) основываясь на отношении доходности и риска (У. Шарп, С.Г. Шматко, В.В. Бочаров);

4) основываясь на комплексной сравнительной оценке (Г.Л. Игольников, Н.Ю. Брызгалова, В.А. Миляев, Е.В. Беляев);

5) на основе стоимостного подхода, где определяющим критерием ИПП является его рыночная стоимость и тенденции к максимизации стоимости (А.Г.Бабенко, С.В.Нехаенко, Н.Н. Петухова, Н. В. Смирнова).

Проведем оценку инвестиционной привлекательности одного из предприятий Пензенской области, взяв за основу методику № 1 (анализ финансовых показателей компании).

Для более объективного анализа проведем оценку финансовых показателей предприятия за последние три года.

ОАО «Электромеханика»- успешное и динамично развивающееся промышленное предприятие, которое с 1961 года производит высокотехнологичные информационно- измерительные системы.

Основные направления ОАО «Электромеханика»:

- бортовые информационно-измерительные системы для

- железнодорожного транспорта;

- автоматизированные системы управления дорожным движением и

- периферийное оборудование.

Также предприятие ОАО «Электромеханика»:

- оказывает услуги по механической обработке изделий и лазерной резке;
- предоставляет сервисное обслуживание (метрологическая поверка и гарантийный ремонт);

- оказывает услуги по пуско-наладочным работам;

- проводит обучение специалистов по ремонту и обслуживанию

- оборудования, производимого предприятием;

- предоставляет в аренду складские, офисные и производственные помещения.

Среди заказчиков локомотивного оборудования ОАО «Электромеханика» более 80 российских и зарубежных железных дорог, промышленных, локомотивостроительных и ремонтных предприятий.

Система менеджмента качества на предприятии существовала всегда, а начиная с 1998 года, в компании было принято решение привести ее в соответствие с Международным стандартом ISO 9001. В марте 2019 года в рамках первого надзорного аудита DQS OAO «Электромеханика» подтвердило соответствие системы менеджмента бизнеса стандарту ISO/TS22163:2017 (IRIS), увеличив уровень развития предприятия до $74 \%$ [5].

Анализ структуры актива и пассива за 20162018 гг. предприятия ОАО «Электромеханика» представлен на рисунках 1 и 2 соответственно.

Анализируя актив баланса, можно сделать вывод, что оборотные активы преобладают над внеоборотными, что свидетельствует о финансовой устойчивости субъекта, т.к. оборотные активы более ликвидны, поэтому способны принести деньги в короткое время. Однако в части оборотных активов наблюдается рост дебиторской задолженности, что может привести к сни-

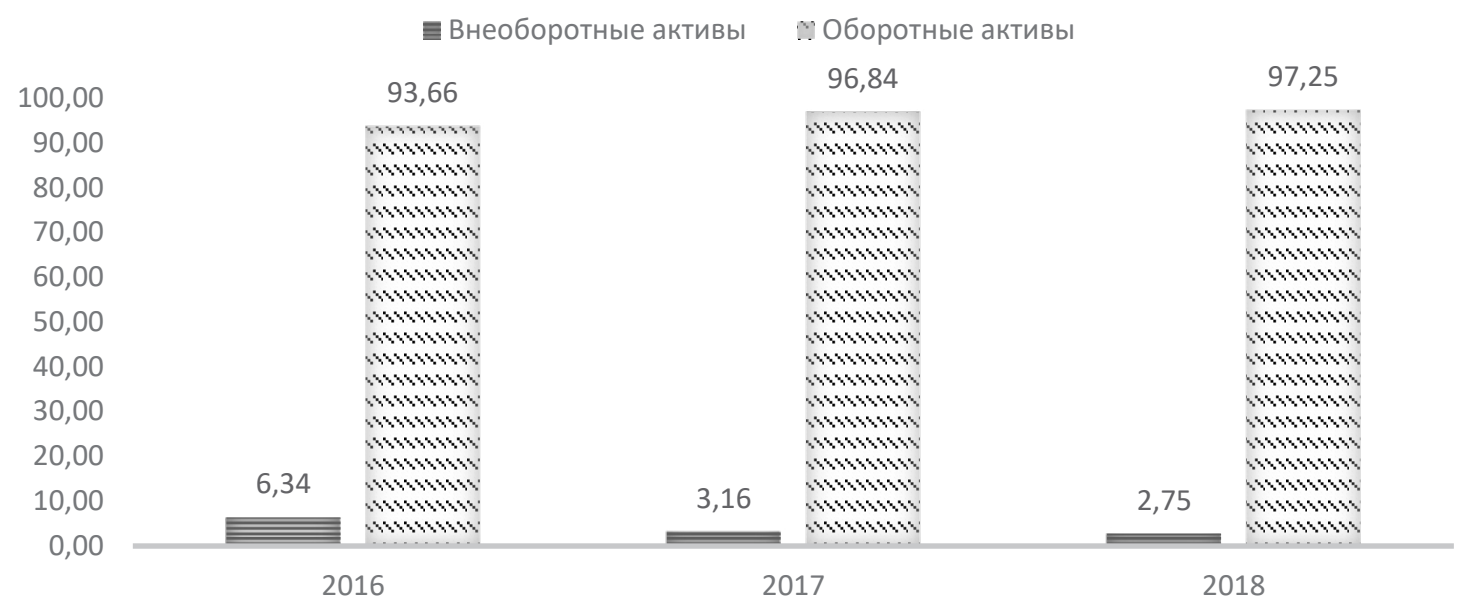

Рuс. 1. Актив баланса 
100,00

90,00

80,00

70,00

60,00

50,00

40,00

30,00

20,00

10,00

0,00
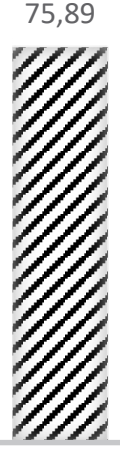

2015
83,39

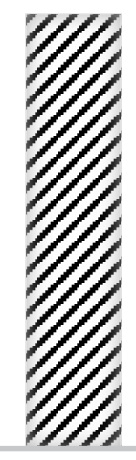

2016
80,07

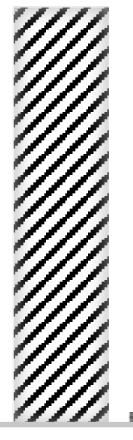

2,37

17,56
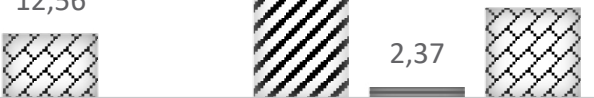

2017

Puc. 2. Пассив баланса

жению инвестиционной привлекательности и деловой репутации.

На основе анализа пассивов баланса в части капитала было выявлено увеличение нераспределенной прибыли, свидетельствующее о росте стоимости бизнеса, о расширении возможностей пополнения оборотных средств для ведения эффективной финансово-хозяйственной деятельности, что положительно влияет на инвестиционную привлекательность предприятия.

Анализ финансовой устойчивости предприятия ОАО «Электромеханика» за 2016-2018 гг. представлен в таблице 1.

Анализируя финансовую устойчивость предприятия, можно сделать вывод, что ОАО «Электромеханика» платежеспособно, рационально использует заемные средства и имеет высокую доходность текущей деятельности.

Расчет и анализ коэффициентов финансовой устойчивости ОАО «Электромеханика» за 20162018 гг. представлен в таблице 2.

Таким образом, ОАО «Электромеханика» является финансово устойчивым предприятием. Предприятие в достаточной степени финансо- во независимо от внешних источников финансирования. Преимущество подобной ситуации состоит в наличии у предприятия резервов для покрытия заемных обязательств в долгосрочной перспективе. Также положительным фактором являются высокие значения коэффициента маневренности собственного капитала, которые свидетельствуют, что предприятию удастся избежать срывов в работе при каких-либо изменениях внешних условий.

Показатели деловой активности ОАО «Электромеханика» за 2016-2018 гг. представлены в таблице 3.

Далее, согласно выбранной методике, необходимо оценить платежеспособность и ликвидность предприятия ОАО «Электромеханика».

В таблице 4 представлен расчёт коэффициентов ликвидности ОАО «Электромеханика» за 2016-2018 гг.

Высокие значения коэффициента текущей ликвидности свидетельствуют о том, что у предприятия оборотных активов больше, чем краткосрочных обязательств. Предприятие имеет высокую способность в краткосрочном периоде

Таблица 1. Анализ финансовой устойчивости предприятия ОАО «Электромеханика» за 2016-2018 гг., тыс. руб.

\begin{tabular}{|c|c|c|c|}
\hline \multicolumn{4}{|l|}{ Анализ финансовой устойчивости } \\
\hline Наименование показателей & 2016 г & 2017 г & 2018 г \\
\hline Наличие собственных оборотных средств на конец расчетного периода & 255258 & 371528 & 507361 \\
\hline Наличие собственных и долгосрочных источников финансирования запасов & 282184 & 390298 & 522903 \\
\hline Общая величина основных источников формирования запасов & 343721 & 448459 & 638101 \\
\hline Излишек (+), недостаток (-) собственных оборотных средств & -88463 & -76931 & -130740 \\
\hline $\begin{array}{l}\text { Излишек (+), недостаток (-) собственных и долгосрочных источников } \\
\text { финансирования запасов }\end{array}$ & -61537 & -58161 & -115198 \\
\hline
\end{tabular}


Таблица 2. Динамика коэффициентов финансовой устойчивости ОАО «Электромеханика» за 2016-2018 гг.

\begin{tabular}{|c|c|c|c|c|}
\hline Коэффициенты & $\begin{array}{l}\text { Интервал } \\
\text { отклонений }\end{array}$ & 2016 г & 2017 г & 2018 г \\
\hline Коэффициент автономии & $\geqslant 0,5$ & 0,76 & 0,84 & 0,80 \\
\hline Коэффициент финансовой зависимости & $>0,7$ & 0,33 & 0,21 & 0,28 \\
\hline Коэффициент соотношения заемных и собственных средств & $<0,7$ & 0,32 & 0,20 & 0,25 \\
\hline $\begin{array}{l}\text { Коэффициент обеспеченности собственными оборотными } \\
\text { средствами }\end{array}$ & $>0,1-0,5$ & 0,74 & 0,83 & 0,80 \\
\hline Коэффициент маневренности & $>0,2-0,5$ & 0,92 & 0,96 & 0,97 \\
\hline $\begin{array}{l}\text { Коэффициент соотношения мобильных и иммобилизованных } \\
\text { средств }\end{array}$ & - & 14,77 & 30,65 & 35,41 \\
\hline Коэффициент прогноза банкротства & $\geqslant 0,5$ & 0,77 & 0,84 & 0,80 \\
\hline
\end{tabular}

Таблица 3. Показатели деловой активности ОАО «Электромеханика» за 2016-2018 гг.

\begin{tabular}{|l|c|c|c|}
\hline \multicolumn{1}{|c|}{ Наименование показателей } & 2016 г & 2017 г & 2018 г \\
\hline Чистая прибыль, тыс. руб. & 41617 & 107634 & 139223 \\
\hline Коэффициент финансового рычага & 0,32 & 0,20 & 0,25 \\
\hline Коэффициент оборачиваемости оборотного капитала в оборотах & 1,58 & 1,62 & 1,42 \\
\hline Средняя длительность одного оборота в днях & 227,25 & 222,34 & 253,23 \\
\hline Коэффициент оборачиваемости дебиторской задолженности & 4,26 & 4,40 & 2,79 \\
\hline Оборачиваемость дебиторской задолженности в днях & 86 & 83 & 131 \\
\hline Коэффициент оборачиваемости кредиторской задолженности & 8,85 & 12,85 & 8,03 \\
\hline Коэффициент оборачиваемости собственного капитала & 1,95 & 1,88 & 1,73 \\
\hline
\end{tabular}

Таблица 4. Коэффициенты ликвидности ОАО «Электромеханика» за 2016-2018 гг.

\begin{tabular}{|c|c|c|c|c|c|c|}
\hline \multirow[b]{2}{*}{ Коэффициенты } & \multirow{2}{*}{$\begin{array}{l}\text { Интервал } \\
\text { значений }\end{array}$} & \multicolumn{3}{|c|}{ Годы } & \multicolumn{2}{|c|}{ Изменение } \\
\hline & & 2016 & 2017 & 2018 & $\begin{array}{c}2016 \text { г от } \\
2017 \text { г }\end{array}$ & $\begin{array}{c}2017 \text { г от } \\
2018 \text { г }\end{array}$ \\
\hline Коэффициент текущей ликвидности & $1 \geqslant$ Кт.л. $\geqslant 2$ & 5,59 & 7,71 & 5,54 & $+2,13$ & $-2,17$ \\
\hline Коэффициент срочной ликвидности & $\geqslant 1$ & 3,47 & 4,85 & 3,71 & $+1,38$ & $-1,14$ \\
\hline Коэффициент абсолютной ликвидности & $\geqslant 0,2-0,5$ & 1,39 & 2,01 & 0,88 & $+0,62$ & $-1,13$ \\
\hline $\begin{array}{l}\text { Коэффициент ликвидности товарно- } \\
\text { материальных ценностей }\end{array}$ & $0,5-0,7$ & 2,11 & 2,86 & 1,83 & $+0,75$ & $-1,03$ \\
\hline
\end{tabular}

расплатиться по своим обязательствам.

Таким образом, коэффициенты ликвидности характеризуют высокую платежеспособность и ликвидность и находятся в зоне оптимальных значений.

Показатели рентабельности ОАО «Электромеханика» за 2016-2018 гг. представлены в таблице 5 .

Коэффициент рентабельности основной деятельности свидетельствует о том, что предприятие установило оптимальные цены на свою продукцию и в усилении контроля за себестои- мостью реализованной продукции нет необходимости.

По мнению авторов, для объективной и более полной оценки ИПП дополнительно к выбранной методике необходимо провести оценку таких показателей как: общая экономическая эффективность капитальных вложений, коэффициент покрытия инвестиций и коэффициент инвестиционной активности.

Общая экономическая эффективность капитальных вложений измеряется двумя показателями: коэффициентом эффективности 
Таблиц̧а 5. Показатели рентабельности ОАО «Электромеханика» за 2016-2018 гг.,\%

\begin{tabular}{|l|c|c|c|}
\hline \multicolumn{1}{|c|}{ Наименование показателей } & 2016 г & 2017 г & 2018 г \\
\hline Рентабельность продаж & 7 & 17 & 17 \\
\hline Рентабельность собственного капитала & 15 & 28 & 26 \\
\hline Рентабельность основной деятельности & 8 & 21 & 7,73 \\
\hline Рентабельность внеоборотных активов & 1,79 & 7,36 & 21 \\
\hline Рентабельность активов & 11 & 23 & 22 \\
\hline Рентабельность оборотного капитала & 12 & 24 & 5,17 \\
\hline Эффект финансового рычага (DFL) & 3,60 & 4,51 & \\
\hline
\end{tabular}

Таблица 6. Показатели инвестиционной привлекательности ОАО «Электромеханика» за 2016-2018 гг.

\begin{tabular}{|l|c|c|c|}
\hline \multicolumn{1}{|c|}{ Наименование показателей } & 2016 г & 2017 г & 2018 г \\
\hline Коэффициент эффективности капитальных вложений & 3,25 & 11,60 & 12,70 \\
\hline Срок окупаемости капитальных вложений, лет & 4 года & 1 год & 11 мес. \\
\hline Коэффициент покрытия инвестиций & 0,83 & 0,87 & 0,82 \\
\hline Коэффициент инвестиционной активности & 0,53 & 0,74 & 0,68 \\
\hline
\end{tabular}

капитальных вложений и сроком окупаемости капитальных вложений.

Коэффициент покрытия инвестиций показывает, какая часть активов организации финансируется за счет устойчивых источников: собственных средств и долгосрочных пассивов.

Коэффициент инвестиционной активности характеризует долю средств предприятия, направленную на модификацию и усовершенствование собственности и на финансовые вложения в другие организации.

Проведя оценку инвестиционной привлекательности предприятия необходимо отметить следующее: полученные значения коэффициентов финансовой устойчивости, ликвидности, деловой активности, рентабельности, свидетельствуют о наличии большого резерва ликвидности, вследствие чего можно предложить ряд действенных рекомендаций по совершенствованию финансового положения предприятия, а как следствие и повышения инвестиционной привлекательности предприятия ОАО «Электромеханика».

С целью эффективного управления дебитор- ской задолженностью на предприятии должна разрабатываться и быть применима определённая финансовая политика по управлению дебиторской задолженностью. В сложившейся экономической ситуации широко распространенным методом сокращения величины дебиторской задолженности является гибкая система скидок за оплату в срок, которые направлены на своевременное получение денежных средств от заказчиков и партнеров, так как являются стимулятором для более быстрых расчетов. Также возможно применение рефинансирования дебиторской задолженности с помощью факторинга.

Таким образом, предложенные мероприятия по улучшению финансового состояния и инвестиционной привлекательностью ОАО «Электромеханика» будут способствовать повышению имиджа и репутации предприятия перед инвесторами. В результате проделанных мероприятий повысятся рентабельности деятельности, а значит и финансовая устойчивость, и эффективность деятельности в целом.

\section{Библиографический список}

1. Видищева Р.С. Развитие методических основ инвестиционной привлекательности хозяйствующего субъекта на базе финансового анализа [Электронный ресурс]: учебное пособие / Р.С. Видищева.-Электрон. дан.Москва: ФЛИНТА, 2018. - 99 с. - Режим доступа: https://e.lanbook.com/book/110580. - Загл. с экрана.

2. Лаврухина Н.В. Методы и модели оценки инвестиционной привлекательности предприятия // Теория и практика общественного развития. - 2014.- № 8.- С. 113-117. 
3. Нгуен Т.Т. Содержание понятия инвестиционной привлекательности // Известия Тульского государственного университета. Экономические и юридические науки. - 2013. - № 2.- С. 91-96.

4. Савинова О.В., Козина Е.В. Формирование стратегии развития инвестиционного потенциала региона // Региональная экономика: теория и практика. 2010, № 30. С. 49-52.

5. Электромеханика [Электронный ресурс].- Режим доступа: https://www.elmeh.ru/about/ - (дата обращения 04.06.2019 г.) 